\title{
Perspectives from Young South African and Zimbabwean Women on Attributes of Four (Placebo) Vaginal Microbicide Delivery Forms
}

\author{
R. Weinrib ${ }^{1,6}$ (1) E. N. Browne ${ }^{1} \cdot$ M. K. Shapley-Quinn ${ }^{1} \cdot$ A. van der Straten ${ }^{1,2} \cdot$ M. Beksinska $^{3} \cdot$ N. Mgodi $^{4} \cdot$ P. Musara $^{4}$. \\ N. Mphili ${ }^{3} \cdot$ J. L. Schwartz ${ }^{5} \cdot$ S. Ju ${ }^{5} \cdot$ H. Hanif ${ }^{5}$. E. T. Montgomery ${ }^{1}$ on behalf of the Quatro Study Team
}

Published online: 28 June 2019

(c) The Author(s) 2019

\begin{abstract}
Introduction Incorporating end-user input into the design of new vaginal microbicides for women is key to optimizing their uptake, consistent use, and, ultimately, success in combatting the heterosexual HIV epidemic.

Methods The Quatro Study assessed four placebo forms of vaginally inserted HIV-microbicides among young microbicidenaïve African women: on-demand film, insert and gel, and monthly ring. Participants randomly used each product for 1 month and provided product satisfaction ratings (1-5 scale), and opinions on product attributes and potential alternative designs. Qualitative data were collected through focus group discussions at study exit. Multivariable associations between attribute opinions and overall product rating were examined using Poisson regression models with robust standard errors to assess the attributes most influential to satisfaction.

Results Overall opinions of products and their individual attributes were generally positive; all products were rated either 4 or a 5 by $\geq 50 \%$ of participants. Attributes related to ease of use and interference with normal activities were the most salient predictors of satisfaction. Preferences for duration of use tended toward relatively shorter use periods for the ring (i.e., 1-3 months vs. 12 months) and for coitally independent dosing for the on-demand products.

Conclusions How well a product fit in with participants' lifestyles was important to their overall satisfaction. For on-demand products, greater flexibility around timing of use was desired, to avoid coital dependency of the dosing.
\end{abstract}

Keywords Acceptability $\cdot$ End-user research $\cdot \mathrm{HIV}$ prevention $\cdot$ Product attributes $\cdot$ Africa $\cdot$ Microbicides $\cdot$ African women

Electronic supplementary material The online version of this article (https://doi.org/10.1007/s10461-019-02576-8) contains supplementary material, which is available to authorized users.

\section{R. Weinrib}

rweinrib@rti.org

1 Women's Global Health Imperative, RTI International, San Francisco, CA, USA

2 Department of Medicine, Center for AIDS Prevention Studies, University of San Francisco, San Francisco, CA, USA

3 MatCH Research Unit, Department of Obstetrics and Gynaecology, School of Clinical Sciences, University of the Witwatersrand, Durban, South Africa

4 University of Zimbabwe College of Health Sciences-Clinical Trials Research Centre, Harare, Zimbabwe

5 Eastern Virginia Medical School, CONRAD, Arlington, VA, USA

6 RTI Health Solutions, RTI International, Barcelona, Spain

\section{Introduction}

Despite technological advances in HIV prevention approaches, the risk of HIV acquisition among young women in sub-Saharan Africa remains unacceptably high [1]. Over the past decade, several promising biomedical HIV prevention approaches, including vaginal microbicides and oral pills, have been evaluated in sub-Saharan Africa in phase III trials. However, several of these trials were unable to demonstrate effectiveness, or only showed limited levels of protection, in large part due to low product adherence among participants [2-8].

Microbicides applied inside the vagina in various delivery forms, including films, gels, suppositories or inserts, and rings, could provide women with a range of biomedical HIV prevention options $[4,8-11]$. These formulations carry the benefits of being discreet, female-initiated, and could potentially be used without male partner consent. However, they must be liked and consistently used to optimize their impact. 
Adherence and acceptability have been conceptualized as distinct but closely linked [12]. An HIV prevention product that will impact the heterosexual epidemic in Africa must not only be biologically efficacious, but also suitable for the target population of "end-users" from a socio-behavioral perspective [13].

Therefore, focus has increased in HIV-prevention research toward gathering and incorporating end-user input to improve product designs. A key goal of end-user research during product development is to identify modifiable features, product attribute-related challenges, and barriers to product use, to ideally address these issues prior to efficacy trials. Improved HIV prevention product design and understanding of the context of product use among populations at high risk of HIV should improve the likelihood of adherence in trials and maximize the product's uptake after licensure [10].

The Quatro Study assessed acceptability and use of four placebo vaginal delivery forms: film, insert (i.e., vaginal tablet), gel, and ring among young women in Southern Africa. This paper explores several dimensions of product acceptability, including ratings of how much each of the Quatro products was liked and the attributes of products that were acceptable or not. These analyses aim to shed light on the attributes that were salient drivers of overall product satisfaction, and to explore changes that might make vaginal delivery forms more acceptable to women in the future.

\section{Methods}

\section{Study Design and Sample}

The Quatro Study clinical component was a two-stage randomized cross-over acceptability study. In stage one, participants used each of four placebo products for 1 month and returned to the clinic monthly to provide their opinions. Stage two involved choosing one of the four products to use with every sex act for one additional month, with the goal of examining adherence. Here, we present findings from stage one only, which was designed to gather detailed feedback on participants' experiences and satisfaction using each product.

Participants were recruited in Durban, South Africa, from a family planning clinic in the city center and the surrounding community; and in Chitungwiza, Zimbabwe, from family planning clinics, voluntary counseling and testing (VCT) clinics, and community locations such as markets, shopping centers, and informal settlements. One hundred participants were enrolled in each country (total $\mathrm{N}=200$ ) between June and November 2016.

Eligibility criteria were designed to enroll young potential end-users of vaginal microbicide products. Participants were
HIV-negative, sexually-active women between the ages of 18 and 30. Pregnant women and those wanting to become pregnant in the next 6 months were excluded, as were those who had previously participated in microbicide or pre-exposure prophylaxis (PrEP) research. Pregnancy and HIV status were confirmed through laboratory testing at screening.

All study procedures received ethics and regulatory approval in both countries prior to implementation, and all participants provided written informed consent before undergoing any study procedures. At every visit, participants received HIV-risk reduction counseling, were offered condoms, and received explanations reminding them that the products were placebos and provided no protection.

\section{Study Products}

The delivery forms under study in Quatro were all inserted vaginally and included: an on-demand (i.e., used whenever required, in this case, precoitally) gel, insert, and film; and a monthly ring (Fig. 1). Products were provided by CONRAD in Arlington, Virginia, USA. Because the objective of Quatro was to explore delivery form acceptability, uncoupled from concerns about side effects or efficacy that may accompany an active drug, only placebo versions of the products were used.

\section{Procedures}

After enrollment and a baseline questionnaire that collected demographics, behavioral, and product rating information prior to use, participants used all four products for 1 month each in a randomized sequence. In the months they were assigned to use one of the three on-demand products, women inserted the first dose in the clinic with guidance from the clinician, and then received four additional doses to use at home. They were instructed to insert the product in the vagina once a week up to $2 \mathrm{~h}$ before sex or insert the product without sex in any weeks where sex did not occur. The ring was inserted and removed with clinician guidance in the clinic, then inserted once more by the participant herself, with instructions to keep the ring inserted for the entire month. Participants returned to the clinic monthly to receive their next assigned product and complete interviewer-administered acceptability surveys about their experiences over the past month, which included product-specific questions, questions about opinions and preferences around HIV prevention products, and about recent sexual behavior.

A subset of participants in each country joined focus group discussions (FGDs) after their final month in the study. To ensure a variety of perspectives, 40 FGD participants were randomly selected after stratifying by product chosen in stage two. The FGDs were facilitated by a trained 

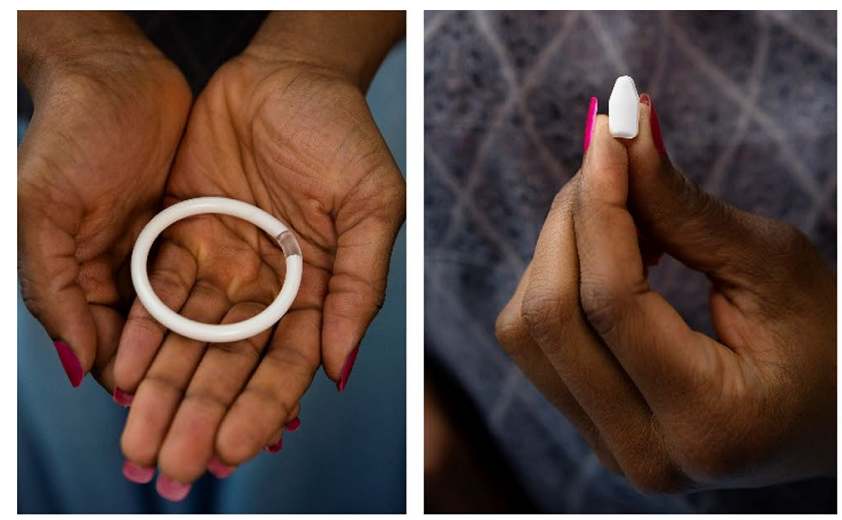

Fig. 1 Quatro Study vaginal products: ring, insert, film, gel. Placebo vaginal delivery forms used in the Quatro Study: a polyurethane ring, a water-based vaginal insert or tablet, a dry gel film, and hydroxyethyl cellulose (HEC) gel (inside an applicator). Additional details on product size: The ring is $55.0 \mathrm{~mm}$ in diameter, with a cross-sectional

interviewer using a semi-structured guide. FGDs were audio-recorded and later transcribed into English.

Throughout the study, staff emphasized to participants the importance of honest feedback, and the impact of their role as product testers, co-designers, and research partners. During stage one, women were told that if they did not like using a product, they were not required to use it for the entire month. They were encouraged to communicate openly with the study staff about product experiences, specifically what they liked and disliked about each product.

\section{Measures}

Demographic characteristics were collected at baseline with a standard questionnaire used in past microbicide and PrEP studies in Africa [2, 4]. A monthly acceptability questionnaire was developed based on formative research and input from the study team, including the product developer. After using each product for 1 month, women were asked for their opinions about its attributes, defined as product-specific characteristics, such as: physical appearance; timing or ease of use; feeling during insertion, sex; and menses. In addition, questions about potential modifications to the product were explored to assess whether a hypothetical alternative design would improve product satisfaction. Opinions about attributes and alternative product designs were provided on a 4-point scale from 1 (very unacceptable) to 4 (very acceptable). The primary outcome of this analysis was the participant's overall satisfaction rating, defined as her assessment of how much she liked each product, rated on a 5-point Likert scale of 1 (dislike very much) to 5 (like very much). See the electronic supplement for sample questions from the monthly acceptability questionnaire.
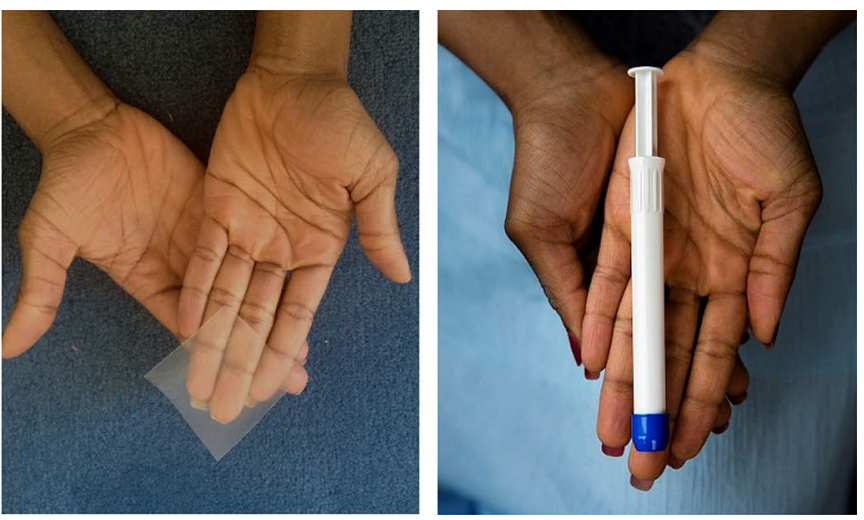

diameter of $5.5 \mathrm{~mm}$. The insert is approximately $7 \mathrm{~mm} \times 15 \mathrm{~mm}$. The film has dimensions of approximately $5 \mathrm{~cm} \times 5 \mathrm{~cm}$, with an approximate thickness of 100-120 $\mu \mathrm{m}$. The gel applicator contains approximately $4 \mathrm{ml}$ of gel

The FGD guide covered questions around use experiences, product features that were most and least liked, and messaging for future marketing.

\section{Analysis}

Participants who rated at least one product were included in the analysis. Demographic characteristics were tabulated by country and overall, and Pearson's Chi square tests were used to assess differences by country.

The distributions of satisfaction ratings after 1 month of use were first examined and presented descriptively for each product. For multivariable analyses, the outcome of product satisfaction was dichotomized into rating the product as a 4 or 5 ("liking" the product) versus rating it as a 3 or lower ("not liking"). The distributions of opinions for nearly all attributes were generally skewed toward positive responses. Therefore, attribute opinions were dichotomized in descriptive and multivariable analyses as a 4 ("very acceptable") versus 3 or lower ("not very acceptable") The assessment of alternative product designs did not exhibit the same positive skew as the attribute opinions. As such, these responses were dichotomized into 3 or 4 ('acceptable', collapsing "very" and "somewhat" categories) versus 1 or 2 ("unacceptable', collapsing "very" and "somewhat" categories), to examine whether a proposed change was viewed negatively or positively overall.

A mixed-effect logistic regression model was used to predict the probability of liking each product by country; the model included a random intercept for randomization sequence and for subject to account for the clustered longitudinal structure of the data. To explore the relationship between product satisfaction and attribute opinions, relative risk ratios were modeled for each product using 
multivariable Poisson regressions with robust standard errors, controlling for country and month of product use. Age was also considered as a potential confounder. Variance inflation factors were used to assess the appropriateness of including all attributes in a single model for each product. All analyses were conducting using Stata [14].

For the qualitative analysis, a codebook was developed based on previous studies [15, 16] and an HIV-prevention product acceptability conceptual model [12]. Two analysts coded transcripts using Dedoose [17], a web-based qualitative analysis software. The analysts used regular inter-rater reliability tests to identify any discrepancies in coding, and all discrepancies were resolved by consensus. Based on the key findings from the quantitative analysis, reports incorporating codes corresponding to product attributes: "physical attributes," "dosing regimen," "route of administration," "use attributes," and "effect on life" were reviewed to further explore participants' opinions and experiences regarding the Quatro products.

\section{Results}

\section{Description of Study Sample}

Of the 200 participants enrolled in the Quatro clinical study, 190 participants $(95 \%)$ rated at least one product and are included in this analysis; 180 participants $(90 \%)$ rated all four products. There were 40 women $(21 \%)$ who participated in focus groups at the end of the study. Demographic characteristics of the analysis sample $(\mathrm{N}=190)$ are presented by country in Table 1 . The median age was 24 (interquartile range 21-26). Nearly all (93\%) participants in South Africa and all (100\%) in Zimbabwe had a primary partner at the time of study enrolment; although, only $11 \%$ of South African participants lived with, or were married to, their partners, compared with $94 \%$ in Zimbabwe ( $\mathrm{p}<0.001)$. Most (87\%) participants had given birth at least once, and the majority $(69 \%)$ had attained a secondary school education or higher. The samples in each country differed from each

Table 1 Baseline characteristics of participants who used all four vaginal placebo products in the Quatro Study, by country (N=190)

\begin{tabular}{|c|c|c|c|}
\hline Characteristic & $\begin{array}{l}\text { South Africa }(\mathrm{N}=91) \\
\%\end{array}$ & $\begin{array}{l}\text { Zimbabwe }(\mathrm{N}=99) \\
\%\end{array}$ & $\begin{array}{l}\text { Total }(\mathrm{N}=190) \\
\%\end{array}$ \\
\hline \multicolumn{4}{|l|}{ Age } \\
\hline Median (IQR)-years & $22(20-25)$ & $24(22-26)$ & $24(21-26)$ \\
\hline $18-24$ & 68 & 55 & 61 \\
\hline $25-30$ & 32 & 46 & 39 \\
\hline Currently has a primary partner* & 93 & 100 & 97 \\
\hline Lives with partner or married*** & 11 & 94 & 54 \\
\hline Currently has a casual sex partner & 9 & 2 & 5 \\
\hline $\begin{array}{l}\text { Ever exchanged sex for money, goods, a place to stay, or } \\
\text { services }\end{array}$ & 3 & 2 & 3 \\
\hline Parity $>0 * * *$ & 73 & 100 & 87 \\
\hline Completed secondary school & 76 & 63 & 69 \\
\hline Earns an income $e^{* * *}$ & 17 & 52 & 35 \\
\hline Attends religious services at least once a week $* * *$ & 68 & 100 & 85 \\
\hline No food insecurity in the past 4 weeks*** & 52 & 86 & 70 \\
\hline Has place for privacy in home & 92 & 96 & 94 \\
\hline \multicolumn{4}{|l|}{ Worried she will contract HIV in next 12 months } \\
\hline Not at all/a little & 51 & 47 & 48 \\
\hline Somewhat/very/extremely & 50 & 54 & 52 \\
\hline \multicolumn{4}{|l|}{ Contraceptive methods ever used } \\
\hline Male condom*** & 92 & 60 & 75 \\
\hline Female condom* & 1 & 7 & 4 \\
\hline Pills*** & 31 & 87 & 60 \\
\hline IUD & 3 & 2 & 3 \\
\hline Implants*** & 15 & 49 & 33 \\
\hline Injectable*** & 70 & 33 & 51 \\
\hline
\end{tabular}

$* \mathrm{p}<0.05 ; * * \mathrm{p}<0.01 ; * * * \mathrm{p}<0.001$ in Chi squared test 
other on many baseline characteristics assessed, including experience with contraceptive methods.

\section{Distributions of Product Satisfaction Ratings}

The distributions of ratings for each product after 1 month of use are presented in Fig. 2. Overall, the products were well liked: $\geq 50 \%$ of participants rated each product either a 4 or 5. Of the 180 who rated all products, all but $2(99 \%)$ rated at least one product 4 or 5 , but there was variability in which products were liked. Only $12 \%$ rated all products 4 or higher.

The probability of liking the film differed significantly by country, with $78 \%$ of women in Zimbabwe assigning it a 4 or 5 , compared to $52 \%$ in South Africa $(\mathrm{p}<0.001)$. Product satisfaction ratings for the other three products did not differ significantly by country. Overall, the film and insert were rated most favorably, with $65 \%$ saying they liked each of the two products. The ring received the fewest favorable ratings; $50 \%$ liked the product $(\mathrm{p}=0.001)$.

Detailed results from stage two, when women were asked to choose a product to use for the final month of the study, are presented elsewhere [18]. In brief, $29 \%$ chose the film, $28 \%$ chose the ring, $26 \%$ chose the insert, and $16 \%$ chose the gel; Zimbabwean women were significantly more likely to choose the film (45\% vs. $13 \%$ in South Africa). Nearly all $(91 \%)$ chose a product that they liked (rated 4 or 5 in stage one).

\section{Product Attribute Opinions}

Table 2 presents the proportion of participants who said each attribute was "very acceptable," by product. In general, women reported most of the product attributes as very acceptable, with some notable exceptions: less than half said the way the film felt in their hands (49\%), the gel's appearance (45\%), and the timing of the insert (49\%) and gel $(45 \%)$ were very acceptable. Of note, shortly after the study launched, study staff reported that some women were misunderstanding the instruction to use the insert, film, and gel "up to $2 \mathrm{~h}$ before sex", particularly in South Africa: some participants believed they needed to wait for $2 \mathrm{~h}$ after inserting the product before they could have sex. The instructions were clarified soon after the issue was uncovered, but this misperception may have persisted and may have impacted some women's opinions on the timing.

Fewer women found specific attributes of the ring "very acceptable". For example, only the following proportions of women found the appearance (29\%), feeling in hands (35\%), size $(37 \%)$, and feeling inserting into the vagina $(48 \%)$ as very acceptable.

\section{Relationship Between Attribute Acceptability and Overall Product Satisfaction}

Multivariable models were constructed to examine the association between overall satisfaction with the product and acceptability of product attributes (Table 3). The likelihood of rating an attribute "very acceptable" did not differ by age as a continuous variable or by age group (18-24 vs. $25-30$, all $p>0.25$ ), so age was not included in the final models. Variance inflation factors did not indicate any significant correlation between attribute opinions per product (data not shown), hence all attributes were included in the models. Attribute associations, grouped by category, are further explained below. Illustrative quotes from qualitative FGD were used to provide examples of participants' feedback about the attributes, in their own words.

\section{Aspects of Use Experience}

Across all four products, low perceived interference with normal activities was a statistically significant predictor of positive product rating (Table $3 ; \mathrm{p}<0.01$ for all products). The salience of this association was echoed in the qualitative

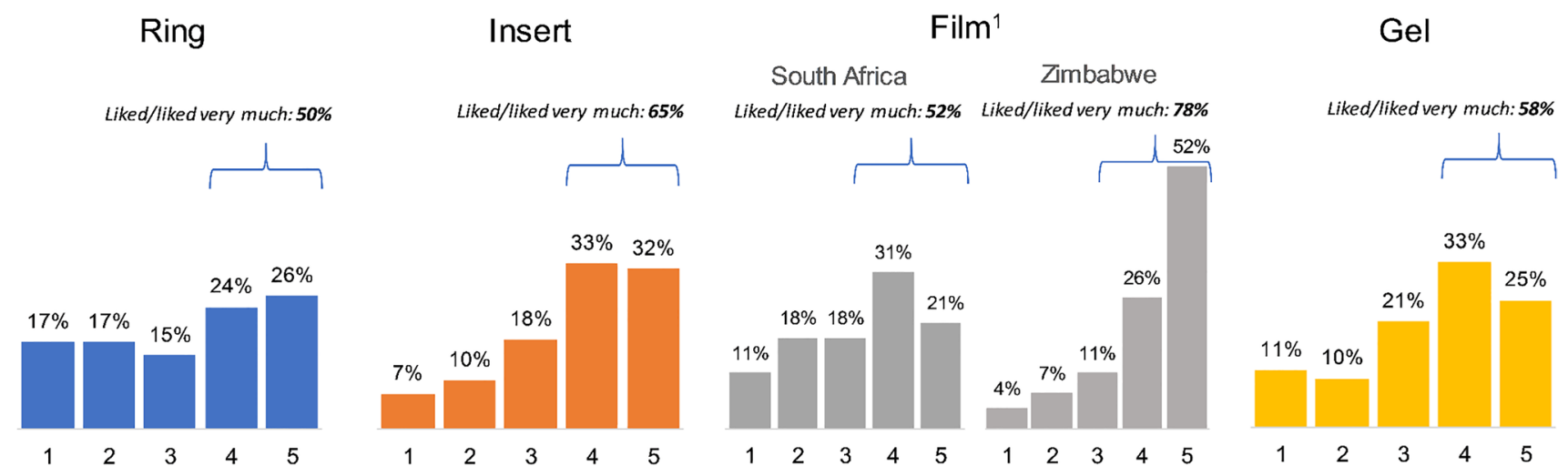

Fig. 2 Distributions of Quatro product satisfaction ratings after 1 month of use ( $1=$ disliked very much; $5=$ liked very much). ${ }^{1}$ The distribution of ratings for the film differed significantly by country $(\mathrm{p}<0.001)$ 
Table 2 Proportion of Quatro participants who reported each product attribute (characteristic) as "very acceptable," by product

\begin{tabular}{|c|c|c|c|c|}
\hline \multirow[t]{2}{*}{ Product attribute } & $\begin{array}{l}\text { Ring } \\
(\mathrm{N}=185)^{\mathrm{b}}\end{array}$ & $\begin{array}{l}\text { Insert } \\
(\mathrm{N}=184)\end{array}$ & $\begin{array}{l}\text { Film } \\
(\mathrm{N}=186)\end{array}$ & $\begin{array}{l}\text { Gel } \\
(\mathrm{N}=186)\end{array}$ \\
\hline & $\mathrm{N}(\%)$ & $\mathrm{N}(\%)$ & $\mathrm{N}(\%)$ & $\mathrm{N}(\%)$ \\
\hline \multicolumn{5}{|l|}{ Aspects of use experience } \\
\hline Interference with normal activities & $113(61)$ & $146(79)$ & $146(78)$ & $138(74)$ \\
\hline Ease of use & $99(54)$ & $144(78)$ & $112(60)$ & $151(81)$ \\
\hline Ease of storage & $111(60)$ & $153(83)$ & $150(81)$ & $150(81)$ \\
\hline Timing of use $\mathrm{c}^{\mathrm{c}}$ & $101(55)$ & $90(49)$ & $97(52)$ & $84(45)$ \\
\hline \multicolumn{5}{|l|}{ Physical features } \\
\hline Appearance & $54(29)$ & $109(59)$ & $99(53)$ & $84(45)$ \\
\hline Size & $69(37)$ & $155(84)$ & $104(56)$ & $115(62)$ \\
\hline \multicolumn{5}{|l|}{ Aspects of feeling and sensation } \\
\hline Reported using during menses & $117(63)$ & $69(38)$ & $56(30)$ & $66(35)$ \\
\hline Feeling during menses ${ }^{\mathrm{d}}$ & $78(67)$ & $48(70)$ & $34(61)$ & $38(58)$ \\
\hline Reported using during sex & $155(84)$ & $154(84)$ & $153(82)$ & $155(83)$ \\
\hline Feeling to participant during sex ${ }^{\mathrm{d}}$ & $95(62)$ & $115(75)$ & $114(75)$ & $88(57)$ \\
\hline $\begin{array}{l}\text { Reported using during sex and disclosed } \\
\text { to partner }\end{array}$ & $129(70)$ & $121(66)$ & $112(60)$ & $122(66)$ \\
\hline Feeling to partner during $\operatorname{sex}^{\mathrm{d}}$ & $80(62)$ & $92(76)$ & $85(76)$ & $73(60)$ \\
\hline Feeling in hands & $65(35)$ & $123(67)$ & $91(49)$ & $94(51)$ \\
\hline Feeling of insertion into vagina & $89(48)$ & $134(73)$ & $94(51)$ & $100(54)$ \\
\hline
\end{tabular}

aPossible response options were "very unacceptable," "somewhat unacceptable," "somewhat acceptable," or "very acceptable"

${ }^{\mathrm{b}}$ The sample size of women completing the acceptability questionnaire differs slightly for each product due to loss to follow up

cTiming of use was presented as the following for ring: "leaving the ring in for an entire month"; and for insert/film/gel: "having to use the [product] up to $2 \mathrm{~h}$ before sex"

${ }^{\mathrm{d}}$ Of participants who reported use during menses/sex data in both countries. For example, in one FGD, a participant said of the ring, "And once you insert it, it will not affect anything. You will just do your work as usual and you will not feel it even the movements." (Zimbabwe, age 24) This sentiment about the ring was echoed by another participant: "People will like it because you don't have to keep inserting, inserting and inserting it." (South Africa, age 24)

Ease of storage was not significantly associated with product rating (Table 3; $\mathrm{p}>0.40$ for all products). Reporting that the product's ease of use was 'very acceptable' was significantly associated with liking the ring (RR 1.58, 95\% CI 1.06, 7.51; $\mathrm{p}=0.02$ ), insert (RR 2.39, 95\% CI 1.33, 4.29; $\mathrm{p}<0.01$ ), and film (RR 1.56, 95\% CI 1.16, 2.09; $\mathrm{p}<0.01$ ); the association was similar for the gel although not statistically significant (RR $1.42,95 \%$ CI $0.82,2.48$; $\mathrm{p}=0.21)$. In describing their experiences with product use, women spoke about differing characteristics (depending on the product) that facilitated ease of use. Women who were happy with the ring pointed to its benefit of only needing to be inserted once at the beginning of the month. One participant said, "It is easy to use because you insert it once. You don't have to worry about a next dose." (South Africa, age 21) Another favored the film, "Because it is invisible, and you are even able to hide it. And it is easy to use it." (South Africa, age 23) Another participant liked the insert's discreetness and ease of use:

...Knowing that you are going to meet [have sex] with your partner, you could just put it in your bra. It is something portable, not difficult, you would just slip it in. It was easy to insert and it was not difficult to dissolve. (Zimbabwe, age 25)

Some women found the gel easy to use due to the applicator, and one woman in South Africa discussed being "used to... vaginal applicators given at the clinic" (South Africa, age 30), such as for vaginal yeast treatments.

Opinions about timing of use were not associated with overall rating for the three on-demand products, but women who found leaving the ring in for an entire month very acceptable were significantly more likely to like the ring (RR 2.24, 95\% CI 1.42, 3.51, p < 0.01). One woman expressed liking this aspect of the ring, saying it was 
Table 3 Multivariable associations between reporting individual product attributes "very acceptable" and overall satisfaction with the product ${ }^{\mathrm{b}}$

\begin{tabular}{|c|c|c|c|c|c|c|c|c|}
\hline \multirow[t]{2}{*}{ Product attribute } & \multicolumn{2}{|c|}{$\begin{array}{l}\text { Model 1: ring } \\
\mathrm{N}=185^{\mathrm{c}}\end{array}$} & \multicolumn{2}{|c|}{$\begin{array}{l}\text { Model 2: insert } \\
\mathrm{N}=182\end{array}$} & \multicolumn{2}{|c|}{$\begin{array}{l}\text { Model 3: film } \\
\mathrm{N}=186\end{array}$} & \multicolumn{2}{|c|}{$\begin{array}{l}\text { Model 4: gel } \\
\mathrm{N}=185\end{array}$} \\
\hline & $\mathrm{RR}$ & $(95 \% \mathrm{CI})$ & $\mathrm{RR}$ & $(95 \% \mathrm{CI})$ & $\mathrm{RR}$ & $(95 \% \mathrm{CI})$ & $\mathrm{RR}$ & $(95 \% \mathrm{CI})$ \\
\hline \multicolumn{9}{|l|}{ Aspects of use experience } \\
\hline Interference with normal activities & $2.14 * *$ & $(1.33-3.43)$ & $\mathbf{2 . 8 3} * *$ & $(1.44-5.58)$ & $1.96 * *$ & $(1.20-3.21)$ & $2.11 * *$ & $(1.26-3.56)$ \\
\hline Ease of use & $1.58 *$ & $(1.07-2.34)$ & $2.39 * *$ & $(1.33-4.29)$ & $1.56 * *$ & $(1.16-2.09)$ & 1.42 & $(0.82-2.48)$ \\
\hline Ease of storage & 1.25 & $(0.85-1.83)$ & 0.94 & $(0.66-1.33)$ & 0.94 & $(0.66-1.33)$ & 0.85 & $(0.59-1.23)$ \\
\hline Timing of use & $2.24 * *$ & $(1.42-3.51)$ & 1.16 & $(0.93-1.45)$ & 0.91 & $(0.67-1.24)$ & 1.00 & $(0.69-1.44)$ \\
\hline \multicolumn{9}{|l|}{ Physical features } \\
\hline Appearance & 1.17 & $(0.83-1.65)$ & 1.13 & $(0.85-1.50)$ & 1.23 & $(0.93-1.63)$ & $1.52 *$ & $(1.09-2.10)$ \\
\hline Size & 0.92 & $(0.66-1.28)$ & 1.17 & $(0.83-1.64)$ & 1.05 & $(0.79-1.40)$ & 0.83 & $(0.65-1.07)$ \\
\hline \multicolumn{9}{|l|}{ Aspects of feeling and sensation } \\
\hline Feeling during menses ${ }^{\mathrm{d}}$ & 1.13 & $(0.77-1.65)$ & 1.10 & $(0.74-1.63)$ & $2.00 *$ & $(1.12-3.56)$ & 0.88 & $(0.61-1.28)$ \\
\hline Feeling to participant during $\mathrm{sex}^{\mathrm{e}}$ & 0.90 & $(0.58-1.41)$ & 1.23 & $(0.82-1.84)$ & 1.39 & $(0.90-2.16)$ & 1.10 & $(0.74-1.64)$ \\
\hline Feeling to partner during $\operatorname{sex}^{\mathrm{f}}$ & 1.09 & $(0.70-1.68)$ & 1.45 & $(0.81-2.62)$ & 0.94 & $(0.68-1.29)$ & $1.63^{*}$ & $(1.03-2.57)$ \\
\hline Feeling in hands & 1.08 & $(0.70-1.65)$ & 0.88 & $(0.65-1.19)$ & 1.14 & $(0.92-1.43)$ & 0.97 & $(0.73-1.28)$ \\
\hline Feeling of insertion into vagina & 1.14 & $(0.75-1.74)$ & 1.00 & $(0.69-1.43)$ & 1.00 & $(0.78-1.29)$ & 1.18 & $(0.86-1.60)$ \\
\hline
\end{tabular}

$* \mathrm{p}<0.05 ; * \mathrm{p}<0.01$

${ }^{a}$ Versus reporting it was very/somewhat unacceptable or somewhat acceptable

${ }^{b}$ Liking the product was defined as rating it a 4 or 5 on a 5-point scale

${ }^{\mathrm{c}}$ The sample size of women completing the acceptability questionnaire and being included in multivariate analyses differs slightly for each product due to loss to follow up and missing data

${ }^{\mathrm{d}}$ Reference group includes women who did not report using the product during menses; this group did not rate the product differently from those who used with menses

${ }^{\mathrm{e}}$ Reference group includes women who did not report using the product with sex; this group did not rate the product differently from those who used with sex

${ }^{\mathrm{f}}$ Reference group includes women who did not report using the product during or did not disclose to their partner, this group did not rate the product differently from those who used with sex and disclosed use to their partners

good because you would just wear it once the whole month. No one would even imagine what will be going on. You won't be seen poking fingers in the vagina, or to say I have forgotten or I have done this. (Zimbabwe, age 29)

\section{Physical Features}

Physical appearance was significantly associated with the gel rating (RR 1.52, 95\% CI 1.09, 2.10, $\mathrm{p}=0.01$ ), but not with rating of the other three products. One FGD participant described concerns she had about the gel based on the appearance of the applicator, saying, "The shape of it I thought it would hurt me when inserting it. And how am I going to push this thing [the applicator]." (South Africa, age 26). In contrast, women discussed liking that the insert was a familiar-looking product (like oral pills), which made it look less "scary."

In FGDs, women who disliked the ring discussed experiencing fear as well as difficulty and discomfort with insertion due to its size. However, opinion of product size was not a significant predictor of the overall product rating (Table 3; $\mathrm{p}>0.15$ for all products).

\section{Aspects of Feeling and Sensation}

High acceptance of how the film felt during menses was significantly associated with its overall rating (RR 2.00, 95\% CI 1.12, 3.56; $p=0.02$ ), but this relationship did not emerge with the other three products. Discussions of how the products felt during menses were not explored and did not arise spontaneously in the FGDs. Of note, only around one-third of participants (30-38\%) reported using the ondemand products during menses.

Although quantitative opinions of product insertion feelings were generally not significant predictors of overall product rating, discourse in the focus groups revealed strong feelings and preferences; the physical feeling of the products during use and their dissolving properties were discussed extensively. Women who disliked the ring pointed to problems with feeling the ring slipping out, causing pain, itching, bleeding, or discomfort during daily activities. Others described liking the insert because it dissolved quickly. 
When discussing the film, participants cited problems with the film dissolving, stickiness, and the edges and corners of the film "poking" or "pricking" during insertion. Other FGD participants complained about the gel feeling cold and causing a lot of discharge that takes some time to come out.

The product attribute of feeling during sex was more salient in the qualitative discussions than in the quantitative analyses, which did not reveal any significant associations with product rating ( $\mathrm{p}>0.18$ for all products). In the FGDs, women spoke about use of all four products during sex, with broad discussions of feeling that product use resulted in changes to the vaginal state (e.g. wetness, dryness, or tightness). However, there were no consistent trends in certain products causing particular vaginal changes, nor was there an overall pattern regarding whether these changes were seen as negative or positive. Some FGD participants said the ring increased sexual pleasure for themselves and/or their partners, while others cited discomfort during sex as a reason for not liking the ring. Women in both countries reported increased wetness due to the insert, which was a positive feature for some women, improving sex, and a negative for others. In contrast, others experienced the insert dissolving slowly, and feeling "sandy" during sex. Some women discussed the film causing dryness during sex or sticking to their partner's penis after sex. Some complained about tightness during sex due to the film, although most saw this as a benefit, reporting overall positive experiences with film use during sex. As one woman explained, "the film is good because it shrinks you back to your virginity." (Zimbabwe, age 26) Some women explained their preference for the gel due to the increased lubrication it provided during sex.

Finally, participants who said the way the gel felt during sex to their partner was very acceptable were significantly more likely to like it overall (RR 1.63, 95\% CI 1.03, 2.57; $\mathrm{p}=0.04$ ). In the FGDs, women described the gel being easily felt by their partner due to the increased wetness it caused. For some, this was a benefit, increasing pleasure during sex, while for others, this caused concerns, such as for this participant: "For me gel was easy on application, but it was not as good on sex because my husband would say it feels like you already had sex, he did not like that slipperiness." (Zimbabwe, age 25)

\section{Alternative Product Designs}

Opinions of alternative product designs are presented in Table 4. In general, a majority of women felt the proposed alternatives would be acceptable. However, there were a few less popular alternatives.

Women preferred the color of the insert and film they used in the study to the proposed alternatives, with less than half (46\%) saying an insert with a color other than white would
Table 4 Opinions of alternative product designs after 1 month of use

\begin{tabular}{|c|c|}
\hline How acceptable would it be to you to have a (product)... & $\begin{array}{l}\text { Somewhat/ } \\
\text { very accept- } \\
\text { able } \\
\mathrm{N}(\%)\end{array}$ \\
\hline Ring & $(\mathrm{N}=185)^{\mathrm{a}}$ \\
\hline ...that changes to show how much of the drug has been released over time? & $162(88)$ \\
\hline ...that you could leave in for 3 months instead of 1 month? & $114(62)$ \\
\hline ...that you could leave in for 12 months instead of 1 month? & $84(45)$ \\
\hline Insert & $(\mathrm{N}=184)$ \\
\hline ...with a color other than white? & $84(46)$ \\
\hline ...that you use up to 1 day before sex instead of up to $2 \mathrm{~h}$ before sex? & $160(87)$ \\
\hline ...that you use up to 1 week before sex instead of up to $2 \mathrm{~h}$ before sex? & $154(84)$ \\
\hline ...that you use after sex instead of up to $2 \mathrm{~h}$ before sex? & $115(63)$ \\
\hline Film & $(\mathrm{N}=186)$ \\
\hline ...that is a color other than clear? & $68(36)$ \\
\hline ...that you use up to 1 day before sex instead of up to $2 \mathrm{~h}$ before sex? & $164(88)$ \\
\hline ...that you use up to 1 week before sex instead of up to $2 \mathrm{~h}$ before sex? & $148(79)$ \\
\hline ...that you use after sex instead of up to $2 \mathrm{~h}$ before sex? & $118(63)$ \\
\hline Gel & $(\mathrm{N}=186)$ \\
\hline ...that is thicker? & $80(43)$ \\
\hline ...that you use up to 1 day before sex instead of up to $2 \mathrm{~h}$ before sex? & $163(88)$ \\
\hline ...that you use up to 1 week before sex instead of up to $2 \mathrm{~h}$ before sex? & $147(79)$ \\
\hline ...that you use after sex instead of up to $2 \mathrm{~h}$ before sex? & $127(68)$ \\
\hline
\end{tabular}

${ }^{a}$ The sample size of women completing the acceptability questionnaire differs slightly for each product due to loss to follow up 
be acceptable, and only $36 \%$ approving of a film that is not clear. Less than half (43\%) felt a gel with a thicker consistency would be acceptable. One suggestion for improving the film that emerged from the FGDs was to make it round, rather than square, to eliminate corners that could poke the vagina. Some women in FGDs recommended offering rings of differing sizes to be "compatible" for different sized women.

Alternate timing requirements for the on-demand products were generally acceptable, with the highest proportion (87-88\%) stating use up to 1 day before sex would be acceptable. For example, one FGD participant expressed this preference, saying, "Maybe it has passed [ $2 \mathrm{~h}$ is over], maybe it is almost $6 \mathrm{~h}$ and you are also irritated. You see, the thing which I have inserted is no longer effective. A day is just alright." (South Africa, age 28) Overall, using an insert, film, or gel after sex was less favorable relative to other proposed alternatives, but still acceptable to approximately two-thirds of participants for each product (63-68\%).

Interest in the ring declined with increased dosing duration, with $62 \%$ indicating a 3-month ring would be acceptable and $45 \%$ indicating a 12 -month ring would be acceptable. FGD participants in both countries indicated they would accept a ring worn for more than 1 month if it were more comfortable-smaller in size, more flexible, and designed so that it doesn't move around in the vagina. A participant explained:

Let it [the ring] be changed also and become a bit smaller or even the texture, can it be made into something slippery so that it becomes easy to insert [laughs], and even softer. Haa! that way even if it is to spend 3 months or the whole year inserted it will still be fine. (Zimbabwe, age 26)

Reacting to the proposed longer duration, one participant (South Africa, age 24) also mentioned concerns about STIs or smells that could require monthly changing of the ring.

\section{Discussion}

In this study we uncovered three key findings about the acceptability of four placebo vaginal microbicides among young women in Southern Africa. First, all the products were generally well-liked, and opinions of individual product attributes were also positive. Secondly, attributes related to the ease of use and (non-)interference with normal activities were the most salient predictors of overall product rating. Finally, preferences for timing of use revealed two important points. First, longer periods of use are not always the most acceptable, as the 1- and 3-month rings were more favorable than the 12-month ring. Secondly, for single-use products, timing that would not require coital dosing emerged as the most favored regimen, in part due to the spontaneity of sex, but also driven by desires for the product to have sufficient time to fully dissolve or disappear and not be noticeable during sex. This feedback expressed by some participants in FGDs raises a potential concern regarding the feasibility of meeting this need for discretion with an effective microbicide, given that the active pharmaceutical ingredients must still be present in the vagina for them to work.

In previous studies assessing acceptability of potential intravaginal methods for HIV prevention, including diaphragms, gels, and rings, women's opinions have generally been very positive, particularly when measured quantitatively [8, 19-22]. Here, we found that women reported liking all the products, with the film more highly rated in Zimbabwe. In addition, though satisfaction was generally high, it was more nuanced than previously reported in studies of similar products. We hypothesize this was due to our messaging to women focused on their role as co-designers and the importance of candid feedback, especially telling us what they did not like. Many women in this study were willing to report that they did not like a product, which increased our confidence in their candor. However, an alternative explanation may be that the single month of use (in contrast to longer periods in other studies) did not provide sufficient time for women to grow accustomed to the products. It is a possibility that ratings may have differed given longer periods of use. In general, individual attributes were also acceptable to our participants, though some specific features were less favorable, more so for the attributes of the ring than the other products.

An important aspect of end-user research to consider in light of these results is that positive product or attribute opinions do not guarantee consistent use of a product [23]. Other contextual factors within the conceptual realm of product acceptability must be considered to more fully understand women's decision making processes involved in HIV prevention, and to ensure that beyond being liked, these products are optimized for correct and consistent use [12]. This disconnect has emerged in past studies; for example, two separate studies of diaphragms and gels in Southern Africa found high product acceptability but low consistent use, with factors related to male partners (refusal, disclosure, perceived approval) emerging as prominent drivers of use $[22,24]$. In our multivariable models, acceptability of each product was associated with how easy and non-interfering their use was, suggesting a linkage between use and acceptability; male partners' acceptability was only associated with ratings for the gel. Partner opinions emerged as a more influential factor in the focus group discussions. Of note, roughly $20 \%$ of women did not use the products with sex, which limited our ability to assess male partner influence.

Another key finding from these data was that use-related attributes, such as ease of use and interference with daily life, were more salient with product satisfaction than the physical features of the products. This result was likely due, in part, to the study design, in which participants were asked to use 
each product. Attributes relating to how well the product fit in with their lifestyle then became more evident. Physical features may play an important role during the "first impression" stage of product introduction, prior to uptake and usage. In a separate analysis from this study of product choice and preference [18], participant's most preferred product shifted prior to and following introductory informational sessions and again after use, implying that information and experience changed opinions about the products. Our results corroborate other studies of female-controlled HIV prevention methods that have reported practical aspects of use to be an important driver of product acceptability and adherence [25, 26].

Participants had varied opinions about product timing. For on-demand products, greater flexibility was desired, mainly so that women could be prepared for situations when sex was not planned or scheduled. Participants most preferred an insert, film, or gel that could be used up to 1 day or 1 week before sex, to avoid the coital dependency of the dosing. This is consistent with previous studies that have highlighted challenges presented by women's uncertainty around timing of sex and need for discretion [2, 27]. While $62 \%$ of participants said a ring that would stay inserted for 3 months as opposed to 1 month would be acceptable, a higher proportion accepted the timing of the 1-month ring. When longer durations of use (1 year) were proposed for the ring, the proportion stating the duration would be acceptable decreased. While there is some evidence that longeracting HIV prevention products, such as injections, are more favored by end-users [28-32], longer may not translate into better for the ring, as women may not want to leave the ring inserted beyond 1 month due to hygiene or comfort concerns. This nuance warrants closer examination in future research to determine the optimal duration for different products, as well as counseling around hygiene, acceptable intermittent removals for menses and other concerns, given that longer-acting products are currently in development [33].

\section{Strengths and Limitations}

A major strength of this study is that we collected female participants' opinions of the four delivery forms following actual experiences with the products, rather than hypothetical product presentations. We recruited sexually active women only, and instructed them to use the products with sex, which allowed us to gather feedback based on the full product use experience and explore the potential influences of male partners' perspectives. In addition, because this study was not a clinical trial, we did not strongly emphasize adherence to the dosing regimens, which possibly enhanced participants' openness and honesty to provide product feedback. Less pressure to perfectly adhere to product use may have led to less misreporting of adherence or inflated acceptability measures reported in clinical microbicide trials [34]. As described above, throughout the study, staff reiterated the participants' role as co-designers and reminded them that their feedback about not only what they liked, but what they did not like, could inform the product design for other women in the community.

Nevertheless, this study has several limitations. Given the sample size, statistical power was insufficient to explore nuances around product attributes that were well-liked overall. Although the use of placebo products was by design to focus opinions on the delivery form separated from the active pharmaceutical ingredients, this nevertheless limits the generalizability of our results to eventual active products. Our design prevents us from evaluating acceptability and tolerability of side effects that may accompany active products, or, conversely, the reward of potential or certain protection from HIV. As mentioned above, not all participants used the products during sex, limiting our ability to assess the products the way they would be used in a real world setting. Finally, the brief period of misunderstanding surrounding how to use the precoital products at the beginning of the study may have impacted some participants' opinions of the on-demand products. Nevertheless, the on-demand products were rated highly.

\section{Conclusion}

A key message from this end-user study is that various intravaginal dosage forms of HIV prevention, administered both on-demand and monthly were liked, with no clear favorite. The study highlighted the importance of offering vaginal microbicide products that can easily be used and incorporated into women's lifestyles. Ideally, like contraceptives, an array of on-demand and longer-acting HIV prevention products will be available to appropriately cater to the varied needs of women throughout different stages of their sexual relationships and reproductive lives.

Acknowledgements This study was made possible by the generous support of the American people through the United States Agency for International Development (USAID) through a Contract (MAPS215-053) under a Cooperative Agreement (AID-OAA-A-14-00010) to CONRAD, Eastern Virginia Medical School and a grant from the Bill $\&$ Melinda Gates Foundation (GSB-S-15-001). The views expressed by the author(s) do not necessarily reflect the views of USAID, the United States Government, the Bill \& Melinda Gates Foundation, Eastern Virginia Medical School or CONRAD.

Open Access This article is distributed under the terms of the Creative Commons Attribution 4.0 International License (http://creativeco mmons.org/licenses/by/4.0/), which permits unrestricted use, distribution, and reproduction in any medium, provided you give appropriate credit to the original author(s) and the source, provide a link to the Creative Commons license, and indicate if changes were made. 


\section{References}

1. Harrison A, Colvin CJ, Kuo C, Swartz A, Lurie M. Sustained high HIV incidence in young women in Southern Africa: social, behavioral, and structural factors and emerging intervention approaches. Curr HIV/AIDS Rep. 2015;12(2):207-15.

2. Marrazzo JM, Ramjee G, Richardson BA, et al. Tenofovir-based preexposure prophylaxis for HIV infection among African women. N Engl J Med. 2015;372(6):509-18.

3. van der Straten A, Brown ER, Marrazzo JM, et al. Divergent adherence estimates with pharmacokinetic and behavioural measures in the MTN-003 (VOICE) study. J Int AIDS Soc. 2016;19(1):20642.

4. Baeten JM, Palanee-Phillips T, Brown ER, et al. Use of a vaginal ring containing dapivirine for HIV-1 prevention in women. N Engl J Med. 2016;375(22):2121-32.

5. Rees H, Delany-Morelwe S, Lombard C, et al. FACTS 001 Phase III trial of pericoital tenofovir $1 \%$ gel for HIV prevention in women. In: Paper presented at: Conference on Retroviruses and Opportunistic Infections, Boston 2015.

6. McCormack S, Ramjee G, Kamali A, et al. PRO2000 vaginal gel for prevention of HIV-1 infection (Microbicides Development Programme 301): a phase 3, randomised, double-blind, parallelgroup trial. Lancet. 2010;376(9749):1329-37.

7. Karim SSA, Richardson BA, Ramjee G, et al. Safety and effectiveness of BufferGel and 0.5\% PRO2000 gel for the prevention of HIV infection in women. AIDS (London, England). 2011;25(7):957.

8. Abdool Karim Q, Abdool Karim SS, Frohlich JA, et al. Effectiveness and safety of tenofovir gel, an antiretroviral microbicide, for the prevention of HIV infection in women. Science. 2010;329(5996):1168-74.

9. Bunge KE, Dezzutti CS, Rohan LC, et al. A phase 1 trial to assess the safety, acceptability, pharmacokinetics, and pharmacodynamics of a novel dapivirine vaginal film. J Acquir Immune Defic Syndr. 2016;71(5):498-505.

10. Littlefield S, Zhang W, Schwartz J, et al. Clinical performance, acceptability, and optimization of fast-dissolve vaginal inserts designed for HIV-prevention: results from two clinical studies. In: Conference on HIV Research for Prevention (HIV R4P). Chicago, IL; 2016.

11. Rohan LC, Sassi AB. Vaginal drug delivery systems for HIV prevention. AAPS J. 2009;11(1):78-87.

12. Mensch B, van der Straten A, Katzen L. Acceptability in microbicide and PrEP trials: current status and a reconceptualization. Curr Opin HIV AIDS. 2012;7(6):534-41.

13. Amico KR. Adherence to preexposure chemoprophylaxis: the behavioral bridge from efficacy to effectiveness. Curr Opin HIV AIDS. 2012;7(6):542-8.

14. Stata Statistical Software: Release 15 [computer program]. Version 15. College Station, TX: StataCorp LLC; 2017.

15. Montgomery ET, van der Straten A, Chitukuta M, et al. Acceptability and use of a dapivirine vaginal ring in a phase III trial. AIDS. 2017;31(8):1159-67.

16. Minnis A, Roberts S, Agot K, et al. End-user research on Multipurpose Prevention Technologies (MPT) for HIV and pregnancy prevention: young women's ratings of three delivery forms in a randomized, cross-over study in Kenya and South Africa Paper presented at: International AIDS Society, Paris; 2017.

17. Dedoose [computer program]. Version 7.0.23. Los Angeles, CA; 2016.

18. Montgomery ET, Beksinska M, Mgodi N, et al. End-user preference for and choice of four vaginally delivered HIV prevention methods among young women in South Africa and Zimbabwe: the Quatro Clinical Crossover Study. J Int AIDS Soc. 2019;22(5):e25283.
19. Montgomery ET, Noguchi LM, Dai JY, et al. Acceptability of and adherence to an antiretroviral-based vaginal microbicide among pregnant women in the United States. AIDS Behav. 2018;22(2):402-11.

20. Nel A, Bekker LG, Bukusi E, et al. Safety, acceptability and adherence of dapivirine vaginal ring in a microbicide clinical trial conducted in multiple countries in sub-saharan Africa. PLoS ONE. 2016;11(3):e0147743.

21. van der Straten A, Montgomery E, Cheng H, et al. High acceptability of a vaginal ring intended as a microbicide delivery method for HIV prevention in African women. AIDS Behav. 2012;16(7):1775-86.

22. Montgomery ET, Woodsong C, Musara P, et al. An acceptability and safety study of the Duet cervical barrier and gel delivery system in Zimbabwe. J Int AIDS Soc. 2010;13(1):30.

23. Minnis AM, Shiboski SC, Padian NS. Barrier contraceptive method acceptability and choice are not reliable indicators of use. Sex Transm Dis. 2003;30(7):556-61.

24. Montgomery ET, Cheng H, van der Straten A, et al. Acceptability and use of the diaphragm and Replens ${ }^{\circledR}$ lubricant gel for HIV prevention in Southern Africa. AIDS Behav. 2010;14(3):629-38.

25. Eakle R, Bourne A, Jarrett C, Stadler J, Larson H. Motivations and barriers to uptake and use of female-initiated, biomedical HIV prevention products in sub-Saharan Africa: an adapted metaethnography. BMC Public Health. 2017;17(1):968.

26. Van der Straten A, Shapley-Quinn M, Reddy K, et al. Favoring "Peace of Mind": a qualitative study of african women's HIV prevention product formulation preferences from the MTN-020/ ASPIRE Trial. AIDS Patient Care STDs. 2017;31(7):305-14.

27. Roberts ST, Heffron R, Ngure K, et al. Preferences for daily or intermittent pre-exposure prophylaxis regimens and ability to anticipate sex among HIV uninfected members of Kenyan HIV serodiscordant couples. AIDS Behav. 2014;18(9):1701-11.

28. Luecke EH, Cheng H, Woeber K, et al. Stated product formulation preferences for HIV pre-exposure prophylaxis among women in the VOICE-D (MTN-003D) study. J Int AIDS Soc. 2016;19(1):20875.

29. Minnis AM, Roberts ST, Agot K, et al. Young women's ratings of three placebo multipurpose prevention technologies for HIV and pregnancy prevention in a randomized, cross-over study in Kenya and South Africa. AIDS Behav. 2018;22(8):2662-73.

30. Weinrib R, Minnis A, Agot K, et al. End-users' product preference across three multipurpose prevention technology delivery forms: baseline results from young women in Kenya and South Africa. AIDS Behav. 2018;22(1):133-45.

31. van der Straten A, Agot K, Ahmed K, et al. The Tablets, Ring, Injections as Options (TRIO) study: what young African women chose and used for future HIV and pregnancy prevention. J Int AIDS Soc. 2018;21(3):e25094.

32. Montgomery E, Atujuna M, Ndwayana S, et al. The invisible product: preferences for long-acting injectable and implantable PrEP among South African youth. Paris: International AIDS Society; 2017.

33. Viguers S. 3-month vaginal ring for HIV prevention enters clinical trial: Healio Infectious Disease News; 2017.

34. Montgomery ET, Mensch B, Musara P, et al. Misreporting of product adherence in the MTN-003/VOICE Trial for HIV prevention in Africa: participants' explanations for dishonesty. AIDS Behav. 2017;21(2):481-91.

Publisher's Note Springer Nature remains neutral with regard to jurisdictional claims in published maps and institutional affiliations. 